\title{
Exploring anthropometric and laboratory differences in children of varying ethnicities with celiac disease
}

\author{
Seema Rajani BSc ${ }^{1}$, Abeer Alzaben MSc PhD(c) ${ }^{2}$, Leanne Shirton RN ${ }^{3}$, Rabindranath Persad MBBS FRCPC ${ }^{4}$, \\ Hien Q Huynh MBBS FRACP FRCPC(Hon) ${ }^{4}$, Diana R Mager PhD MSc RD ${ }^{2,5}$, Justine M Turner MBBS FRACP PhD ${ }^{4,6}$
}

S Rajani, A Alzaben, L Shirton, et al. Exploring anthropometric and laboratory differences in children of varying ethnicities with celiac disease. Can J Gastroenterol Hepatol 2014;28(7):351354.

BACKGROUND: Celiac disease (CD) is a common autoimmune disorder with an increasing prevalence, including in ethnic minorities. OBJECTIVE: To report the frequency of CD diagnosis in ethnic minorities presenting to a Canadian pediatric celiac clinic and to determine whether ethnic differences exist at diagnosis or follow-up. METHODS: Patients with biopsy-proven CD diagnosed at a multidisciplinary celiac clinic between 2008 and 2011 were identified through the clinic database. Data at referral, and six-month and 12-month follow-ups were collected. These included demographics, self-reported ethnicity, symptoms, anthropometrics and laboratory investigations, including serum immunoglobulin antitissue transglutaminase (aTTG). RESULTS: A total of 272 patients were identified; $80 \%(n=218)$ were Caucasian (group 1) and 20\% ( $n=54)$ were other ethnicities. South Asians (group 2) comprised $81 \%(n=44)$ of the minority population. No differences in age or sex were found between the two groups. Group 1 patients presented more often with gastrointestinal symptoms ( $71 \%$ versus $43 \% ; \mathrm{P}<0.001$ ), while patients in group 2 presented more often with growth concerns $(21 \%$ versus $68 \% ; \mathrm{P}<0.001)$. At diagnosis, serum aTTG level was consistently lower in group 1 compared with group 2 (367 IU/mL versus $834 \mathrm{IU} / \mathrm{mL} ; \mathrm{P}=0.030)$. Both groups reported symptom improvement at six months and one year. At the end of one year, aTTG level was more likely to be normal in group 1 compared with group 2 (64\% versus $29 \%$; $\mathrm{P}<0.001$ ).

CONCLUSION: Although they represent a minority group, South Asian children comprised a significant proportion of CD patients presenting to a Canadian celiac clinic. South Asian children were more likely to present with growth concerns, which has important implications for timely diagnosis in this population. In addition, the apparent delay in normalization of aTTG levels suggests that careful follow-up and culturally focused education supports should be developed for South Asian children with CD.

Key Words: Caucasian; Celiac Disease; Ethnicity; Pediatrics; South Asian

\section{Explorer les différences anthropométriques et de laboratoire chez des enfants de diverses ethnies atteints de la maladie coeliaque}

HISTORIQUE : La maladie cœliaque (MC) est un trouble autoimmun fréquent à la prévalence croissante, y compris chez les minorités ethniques.

OBJECTIF : Rendre compte de la fréquence de diagnostics de $\mathrm{MC}$ au sein des minorités ethniques qui consultent à une clinique canadienne de $\mathrm{MC}$ en pédiatrie et déterminer s'il y a des différences ethniques au diagnostic ou au suivi.

MÉTHODOLOGIE : Les chercheurs ont répertorié les patients atteints d'une MC confirmée par biopsie dans la base de données cliniques d'une clinique de MC multidisciplinaire entre 2008 et 2011. Ils ont colligé les données lors de l'aiguillage, puis au suivi à six et 12 mois. Ces données incluaient la démographie, l'ethnie autodéclarée, les symptômes, l'anthropométrie et les examens de laboratoire, y compris l'immunoglobuline anti-transglutaminase tissulaire (aTTG) sérique.

RÉSULTATS : Au total, les chercheurs ont dépisté 272 patients, soit $80 \%(n=218)$ de race blanche (groupe 1$)$ et $20 \%(n=54)$ d'autres ethnies. Les Sud-Asiatiques (groupe 2) représentaient $81 \%(n=44)$ de la population minoritaire. Les chercheurs n'ont constaté aucune différence d'âge et de sexe entre les deux groupes. Les patients du groupe 1 étaient plus nombreux à présenter des symptômes gastro-intestinaux (71 \% plutôt que $43 \%$; $\mathrm{P}<0,001)$, tandis que ceux du groupe 2 étaient plus nombreux à avoir des problèmes de croissance $(21 \%$ plutôt que $68 \%$; $\mathrm{P}<0,001)$. Au diagnostic, le taux d'aTTG sérique était constamment plus faible dans le groupe 1 que dans le groupe $2(367 \mathrm{UI} / \mathrm{mL}$ plutôt que $834 \mathrm{UI} / \mathrm{mL} ; \mathrm{P}=0,030)$. Les deux groupes ont déclaré une atténuation des symptômes au bout de six mois et d'un an. À la fin de l'année, le taux d'aTTG était plus susceptible d'être normal dans le groupe 1 que dans le groupe 2 (64 \% plutôt que $29 \%$; $<<0,001$ ).

CONCLUSION : Même s'ils représentent un groupe minoritaire, les enfants sud-asiatiques constituent une proportion importante des patients atteints de $\mathrm{MC}$ qui avaient consulté à une clinique canadienne de MC. Ils étaient plus susceptibles d'avoir des problèmes de croissance, ce qui rendait un diagnostic rapide d'autant plus important. En outre, d'après le retard apparent à normaliser le taux d'aTTG, il faut assurer un suivi attentif et préparer un soutien éducatif adapté à la culture pour ces enfants.

The only known treatment for $\mathrm{CD}$ is complete lifelong elimination of gluten from the diet. Complete mucosal recovery has been shown to occur in children within two years of implemetation of a strict glutenfree diet (GFD) (3). Consequences of not following a GFD include exacerbation of presenting symptoms, and long-term risks of osteoporosis and intestinal lymphoma (4). Similar to any change in lifestyle, a GFD can be difficult and requires support and guidance $(5,6)$. For these reasons, the Stollery Children's Hospital (Edmonton, Alberta) initiated a multidisciplinary celiac clinic for children. This is to ensure
Celiac disease $(C D)$ is an autoimmune disorder that causes damage to the small intestine triggered by the ingestion of gluten (1). CD can have variable presentations including typical gastrointestinal (GI) symptoms such as diarrhea, constipation and abdominal distension. Atypical presentations, with symptoms such as fatigue, headaches, joint problems and mood disturbance, are increasingly recognized (2). $\mathrm{CD}$ is also known to cause malabsorption, which can lead to growth failure, including short stature and failure to thrive, although malnutrition in this population is less common in the current era (2).

\footnotetext{
${ }^{1}$ Department of Pediatrics; ${ }^{2}$ Department of Agricultural, Food 83 Nutritional Science, University of Alberta; ${ }^{3}$ Pediatric Gastroenterology and Nutrition, Multidisciplinary Pediatric Celiac Clinic, Stollery Children's Hospital; ${ }^{4}$ Division of Pediatric Gastroenterology and Nutrition, Department of Pediatrics,

University of Alberta; ${ }^{5}$ Alberta Diabetes Institute; ${ }^{6}$ Multidisciplinary Pediatric Celiac Clinic, Stollery Children's Hospital, Edmonton, Alberta

Correspondence: Dr Justine Turner, Department of Paediatrics, University of Alberta, Edmonton Clinic Health Academy, 11405 87th Avenue, Edmonton, Alberta T6G 1C9. Telephone 780-248 5570, fax 888-353-1157, e-mail justine.turner@albertahealthservices.ca

Received for publication May 12, 2014. Accepted June 9, 2014
} 


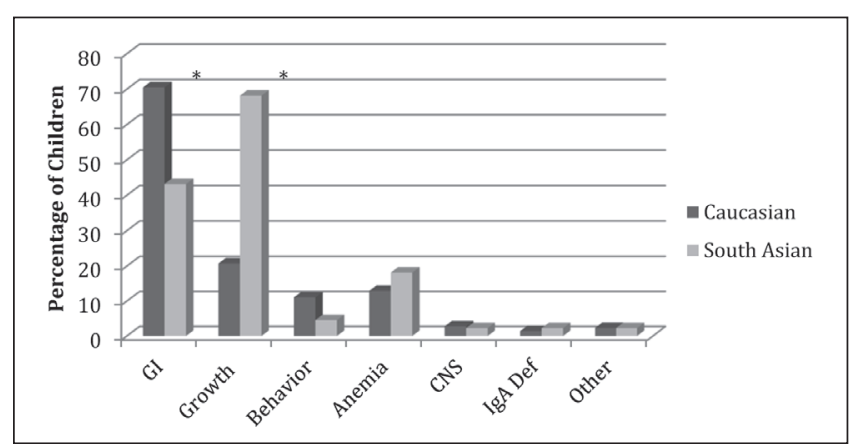

Figure 1) Comparison of symptom presentation between Caucasian and South Asian patients referred for diagnosis of celiac disease at the Stollery Children's hospital in Edmonton, Alberta. ${ }^{*} P<0.001$. CNS Central nervous system; Def Deficiency; GI Gastrointestinal; IgA Immunoglobulin A

children are provided the necessary support and education during and after a positive diagnosis (7).

The prevalence of $\mathrm{CD}$ in North America is estimated to be $1 \%$, with a higher prevalence in first-degree relatives of CD patients (8). $\mathrm{CD}$ was originally believed to be a disease affecting Caucasians (9). However, an increase in the ease of screening using blood tests has enabled the unveiling a large number of cases, especially in India. In Northern India, the prevalence of CD was determined to be one in 96, and it is estimated that five to eight million have CD (10). This is comparable with the estimates from the rest of the world, showing that $\mathrm{CD}$ is just as prevalent in India. However, it is also believed that many $\mathrm{CD}$ patients in India remain undiagnosed or misdiagnosed due to the various clinical presentations that can be associated with CD (11).

The present research was conducted to determine the number of children from ethnic minority groups presenting with $\mathrm{CD}$ to a Canadian pediatric clinic and to determine whether significant differences exist at presentation or follow-up according to ethnic background.

\section{METHODS}

A retrospective chart review was undertaken to identify patients with biopsy-proven $\mathrm{CD}$ diagnosed at the Multidisciplinary Celiac Clinic at the Stollery Children's Hospital between 2008 and 2011. Baseline and follow-up data at six months and one year were collected. These data were obtained from structured interviews at baseline and follow-up, and included demographics, symptoms, anthropometrics and laboratory investigations, specifically serum immunoglobulin A antitissue transglutaminase (aTTG). Anthropometrics included height and weight, in addition to body mass index (BMI) standardized according to WHO AnthroPlus software (12). Weight and height are routinely measured in clinic by trained personnel using standardized and validated methods. Growth concerns were defined in two ways: as a BMIfor-age $z$-score of $<-2 \mathrm{SDs}$; and by parental self-report of 'growth concerns'. Ethnicity was determined through parental self-report during the first medical interview. Ethnicity was categorized according to 2006 Statistics Canada definitions to include Caucasian, South Asian, African and other (Asian or mixed ethnicity) (13).

\section{Statistics}

Statistics were calculated using SPSS version 21 (IBM Corporation, USA) (14). Data are presented as mean \pm SD unless otherwise specified. Student's $t$ tests were used to detect differences between primary outcomes of interest (ethnicity) and age at diagnosis and anthropometric variables. The nonparametric Mann-Whitney test was used for serum aTTG comparisons at each time point of follow-up because these data had a skewed distribution. $\chi^{2}$ tests were used for categorical variables (sex, types of symptoms including GI symptoms, overall symptom improvement, Marsh stage); $\mathrm{P} \leq 0.05$ was considered to be statistically significant.
TABLE 1

Anthropometric and serological comparisons between Caucasian and South Asian patients between 2008 and 2011 at the Multidisciplinary Celiac Disease Clinic for Children at Stollery Children's Hospital, Edmonton, Alberta

\begin{tabular}{lccc}
\hline & Caucasian & South Asian & $\mathbf{P}$ \\
\hline Age, years, mean & 9.2 & 8.2 & 0.170 \\
Sex, male:female, n:n & $85: 133$ & $16: 28$ & 0.744 \\
Body mass index z-score & & & \\
$\quad$ Referral & 0.31 & -0.52 & 0.001 \\
Six months & 0.43 & -0.28 & 0.004 \\
One year & 0.34 & -0.33 & 0.003 \\
aTTG, IU/mL, mean (range) & & & \\
Referral & $367(7.7-4000)$ & $834(11.9-6400)$ & 0.030 \\
Six months & $19(1-260)$ & $388(1.3-5500)$ & 0.002 \\
One year & $8(1-45)$ & $110(1-900)$ & 0.001 \\
\hline
\end{tabular}

Student's t tests were used to determine differences between age at diagnosis, serum immunoglobulin $A$ antitissue transglutaminase (aTTG) levels and body mass index $z$-score according to WHO standards. $x^{2}$ tests were used to calculate differences between sexes

\section{RESULTS}

A total of 272 patients were identified; $80 \%(n=218)$ were Caucasian and $20 \% \quad(n=54)$ were other ethnicities, including South Asian $(n=44)$, African $(n=6)$ and other $(n=4)$. Given the limited sample size and that South Asians comprised $81 \%(n=44)$ of the minority population, subsequent comparisons were only made between the Caucasian (group 1) and South Asian (group 2) children identified.

There were no significant differences in age $(9.2$ years versus 8.2 years; $P=0.170$ ) or sex (male:female ratio $85: 133$ versus $16: 28$; $\mathrm{P}=0.744$ ) between groups 1 and 2 . Caucasian children presented more often with GI symptoms $(71 \%$ versus $43 \%$; $\mathrm{P}<0.001)$ and less often with growth concerns $(21 \%$ versus $68 \%$; $<<0.001)$ (Figure 1 ). South Asian children had a lower BMI $z$-score at referral, six months and one year $(0.31$ versus $-0.52 ; \mathrm{P}<0.001,0.43$ versus $-0.28 ; \mathrm{P}=0.004$, 0.34 versus $-0.33 ; \mathrm{P}=0.003$, respectively;) (Table 1 ). Both groups selfreported a similar number of children/adolescents experiencing symptom improvement by six months and one year (91\% versus $93 \%$; $\mathrm{P}=0.851 ; 88 \%$ versus $90 \% ; \mathrm{P}=0.580)$.

At diagnosis, serum aTTG level was consistently lower in Caucasians compared with South Asians (367 IU/mL versus $834 \mathrm{IU} / \mathrm{mL}$; $\mathrm{P}=0.030$ ). At six-month follow-up, serum aTTG levels remained lower (19 IU/mL versus $388 \mathrm{IU} / \mathrm{mL} ; \mathrm{P}=0.002)$ and also at 12 months $(8 \mathrm{IU} / \mathrm{mL}$ versus $110 \mathrm{IU} / \mathrm{mL} ; \mathrm{P}<001)$. At the end of one year, more Caucasian patients had a normal aTTG level compared with South Asians (64\% versus $29 \% ; \mathrm{P}<0.001)$.

\section{DISCUSSION}

In North America, CD is becoming increasingly recognized due to awareness and screening of high-risk groups (15). The prevalence has increased from one in 1000 in the 1980s to one in 100 in 2004 (16). Given its population diversity, Canadian pediatricians need to know the effect of different conditions on various ethnicities to recognize and treat their patients. There have been few reports of CD involving ethnic minorities, especially in Alberta. The differences in disease presentations among ethnicities and management is under-researched and needs to be further explored to enable the best care and follow-up.

Over time, members of the Pediatric Multidisciplinary Celiac Clinic have noted an increase in referrals of children of South Asian descent. CD in India is believed to be on the verge of an epidemic (17), with the rise of increased and inexpensive screening tools. An increasing number of studies from India show that $\mathrm{CD}$ presents more commonly without classical GI symptoms and more with failure to thrive and anemia (18). 
That CD is only just now being recognized as prevalent in India has implications for CD diagnosis in this population in Canada. Although South Asian children are a minority group in our population, comprising $2 \%$ of Alberta's population, and 3\% (one million) in Canada in 2001 (19), they comprise a significant proportion of patients in our clinic. Furthermore, they tend to present with less typical GI symptoms, but rather to have been screened for poor weight gain. This is important information for primary care providers to facilitate timely screening for $\mathrm{CD}$ in this population.

We found that the presenting symptoms of South Asian children were different to Caucasian children in that they had concerns related to growth rather than GI symptoms. These results mirror those of studies conducted in India. Pooni et al (20) found that patients diagnosed with $\mathrm{CD}$ in the age group $>10$ years more often had short stature compared with those who were diagnosed at a younger age (20). They stress that CD should always be considered when diagnosing a child with slowed growth. In a study from India, Sharma et al (21) found that the classical presentation of CD for patients in India was declining while atypical symptoms related to growth were increasing. The results from these studies, in combination with our own, show that patients of South Asian descent should be screened for CD given short stature or parental concern over their child's growth.

It was noteworthy - and unexpected - that serum levels of aTTG in our study were higher at presentation in South Asian children. It is possible that this could be due to the difference in dietary intake of gluten before diagnosis. In India, more specifically Northern India, grain-based foods are a common dietary staple (9). A typical North Indian diet contains $25 \mathrm{~g}$ to $30 \mathrm{~g}$ of gluten daily, while a Western diet contains approximately $15 \mathrm{~g}$ to $20 \mathrm{~g}$ (22). Another possibility is that due to the atypical presentation of short stature related to CD and lack of GI symptoms, South Asians in our study had a longer duration of disease before diagnosis. Other factors for prolonged time to diagnosis could relate to specific economic and sociocultural factors, such as acculturation, which may impact families seeking medical assistance in general. Unfortunately, duration of symptoms before diagnosis was not recorded in our database; therefore, this is unknown and requires further study. Our study showed no differences in age of presentation between group 1 and group 2 .

Identifying that at least one in five children diagnosed with $\mathrm{CD}$ are of South Asian descent in Canada has implications for resource allocation. A GFD is a lifelong treatment and, similar to any lifestyle change, it requires education and support. Implementation of a GFD early in childhood has been shown to increase adherence to the GFD (5). In childhood, most dietary education is directed at parents and we note that most of our South Asian parents did not speak English as a first language. Furthermore, most resources for CD, particularly glutenfree cookbooks, are published in English. There is a need for culturally focused written resources that target gluten-free foods of ethnically diverse populations. While the dietitian at the Multidisciplinary Celiac Clinic at the Stollery Children's Hospital uses interpreters for teaching sessions, this may well impact the quality of dietary counseling delivered. Language and cultural barriers may need to be addressed to provide optimal support for CD patients from South Asia as well as the availability of gluten-free foods for ethnically diverse populations. There could also be lack of community support with regard to the disease. Support from the community or membership in a local chapter can increase adherence to the GFD and also make the child feel less isolated with their disease (23). Although there are supports, such as a local chapter in Edmonton from the Canadian Celiac Association, it needs to be studied as to how many ethnic minorities reach out to become members as well as what information is available specifically to minorities.

Even when accounting for baseline differences in our study, aTTG levels were slower to normalize, which may reflect all of the above concerns. Alarmingly, in our study, the BMI for South Asians were significantly lower than Caucasian patients; however, they did show some catch-up after a year of a GFD. Therefore, it appears that commencing a GFD improved nutrition in this cohort over one year. A study investigating celiac patients in India by Yachha et al (24) found a mean of 3.2 years for normalization of both nutrition and growth. Longer follow-up and attention to growth may be important for patients of South Asian descent.

While it is tempting to attribute higher initial and later aTTG levels and poorer growth at presentation and one year to greater or exposure to gluten for children with CD from South Asia, it may also be that we are dealing with a difference disease phenotype or behaviour. In a study from Lucknow, India, Yachha et al (24) showed that in Indian children diagnosed with $\mathrm{CD}$, histological recovery was $>5$ years. A factor attributing to this delayed healing was the delay in diagnosis and initiation of a GFD, and inadvertent contamination due to improper labelling. Therefore, timeliness of a CD diagnosis is imperative for the patient not only for their short-term growth and symptom relief but long-term consequences.

A clue into the different behaviour of CD could be found in the genetic background of patients diagnosed with CD. Genes are beginning to play a large role in understanding CD pathology and clinical presentations, especially in diagnosis (25). Studies investigating different genetic susceptibilities in varying ethnicities are few; however, Kaur et al (26) found that there was a difference in haplotypes between Indian population affected by CD and those in the Caucasian population. Butterworth et al (9) also found different human leukocyte antigen alleles when comparing the two ethnic groups, questioning the role of genes in susceptibility of CD.

\section{SUMMARY}

Awareness of $\mathrm{CD}$ is increasing worldwide, and various countries are seeing an increase in its diagnosis in populations (2). Canada is a mosaic of ethnicities, and diseases can affect each differently. We found that the clinical presentation of $\mathrm{CD}$ in South Asians was surrounding growth concerns, while the majority of Caucasian patients had GI concerns. We found that there were differences in aTTG levels at presentation and at one-year follow-up on a GFD, and that South Asians were consistently at higher aTTG levels and slower to normalize. We found a significant difference in the BMI z-scores between Caucasians and South Asians, finding the latter to be significantly lower at presentation but finding some small catchup on a GFD. We are confident that the results from our study can be extended to other cities in Canada where South Asian populations are growing. The need to detect and understand how different ethnicities are affected by CD can help diagnosis of this disease to be made and implementation of treatment to begin earlier allowing for greater success.

DISCLOSURES: The authors have no financial disclosures or conflicts of interest to declare.

\section{REFERENCES}

1. Gujral N, Freeman HJ, Thomson A. Celiac disease: Prevalence, diagnosis, pathogenesis and treatment. World J Gastroenterol 2012;18:6036-59.

2. Fasano A, Catassi C. Current approaches to diagnosis and treatment of celiac disease: An evolving spectrum. Gastroenterology 2001;120:636-51.

3. Wahab P, Meiger J, Mulder JJ. Histologic follow-up of people with celiac disease on a gluten-free diet. Am J Clin Pathol 2002;118:459-63.

4. Smedby KE, Akerman M, Hildebrand H, Glimelius B, Ekborn A, Askling J. Malignant lymphomas in coeliac disease: Evidence of increased risks for lymphoma types other than enteropathy type T cell lymphoma. Gut 2005;54:54-9.

5. Evans KE, Hadjivasilou M, Sanders DS. Understanding 'silent' celiac disease: Complications in diagnosis and treatment. Gastrointest Nurs 2010;8:29-32. 
6. Hoeberg L, Grozinsky E, Stenhammer L. Better dietary compliance in patients with celiac disease diagnosed in early childhood. Scand J Gastroenterol 2003;38:751-4.

7. Rajani S, Sawyer-Bennett J, Shirton L, et al. Patient and parent satisfaction with a dietitian- and nurse-led celiac disease clinic for children at the Stollery Children's Hospital, Edmonton, Alberta. Can J Gastroenterol 2013;27:463-6.

8. Walker MM, Murray JA. An update in the diagnosis of coelic disease. Histopathology 2011;59:166-79.

9. Butterworth JR, Iqbal TH and Cooper BT. Coeliac disease in South Asians resident in Britain: Comparison with white Caucasian coeliac patients. Eur J Gastroenterol Hepatol 2005;17:541-5.

10. Makharia GK, Verma AK, Amarchand R, et al. Prevalence of celiac disease in the northern part of India: A community based study. J Gastroenterol Hepatol 2011;26:894-900.

11. Poddar U, Thapa B, Singh K. Clinical features of celiac disease in Indian children: Are they different from the West? J Pediatr Gastroenterol Nutri 2006;43:313-7.

12. WHO Anthro Plus for personal computers, version 3.2.2,2011: Software for assessing growth and development of the world's children. Geneva: WHO, 2010 <www.who.int/childgrowth/ software/en/> (Accessed March 13, 2014).

13. Statistics Canada. Ethnic Origin Reference Guide, 2006 Census. 2006 Census Analysis Ser. 97-562-GWE2006025. Ottawa, Ont.: Statistics Canada, 2001. <www12.statcan.gc.ca/censusrecensement/2006/ref/rp-guides/ethnic-ethnique-eng.cfm> (Accessed February 18, 2014).

14. IBM Corporation. Released 2012. IBM SPSS Statistics for Macintosh, Version 21.0. Armonk: IBM Corporation.

15. Fasano A, Berti I, Geraduzzi T, et al. Prevalence celiac disease in at risk and not-at-risk groups in the United States: A large multicenter study. Arch Inter Med 2003;163:286-92.
16. Lohi S, Mustalahti K, Kaukinen K et al. Increasing prevalence of coeliac disease over time. Aliment Pharmacol Ther 2007;26:1217-25.

17. Ramakrishna B. Celiac disease: Can we avert the impending epidemic in India? Ind J Med Res 2011;133:5-8.

18. Rawal P, Thapa B, Nain C, Prasad K, Singh K. Changing spectrum of celiac disease in India. Iran J Pediatr 2010;20:459-65.

19. Statistics Canada. Profiles of Ethnic Communities in Canada: The South Asian Community in Canada. 2001 Census Analysis Ser. 89621XIE. Ottawa: Statistics Canada, 2001. <www.statcan.gc.ca/ pub/89-621-x/89-621-x2007006-eng.pdf> (Accessed July 2007).

20. Pooni PA, Chhina RS, Jaina BK, Singh D, Gautam A. Clinical and anthropometric profile of children with celiac disease in Punjab (North India). J Trop Pediatr 2006;52:30-3.

21. Sharma M, Singh P, Agnihotri A, et al. Celiac disease: A disease with varied manifestations in adult and adolescents. J Dig Dis 2013;14:518-25.

22. Price S. Understanding the importance to health of a balanced diet. Nurs Times 2005;101:30-1.

23. Holmes S. Coeliac disease: Symptoms, complications and patient support. Nurs Stand 2010;24:50-6.

24. Yachha S, Srivastava A, Mohindra S, Krishnani N, Aggarwal R, Saxena A. Effect of a gluten-free diet on growth and small-bowel histology in children with celiac disease in India. J Gastroenterol Hepatol 2007;22:1300-5.

25. Husby S, Koletzko S, Korponay-Szabo I, et al. European Society of Pediatric Gastroenterology, Hepatology and Nutrition guidelines for the diagnosis of coeliac disease. J Pediatr Gastroenterol Nutr 2012;54:136-60.

26. Kaur G, Sarkar N, Bhatnagar S, et al. Pediatric celiac disease in India is associated with multiple DR3-DQ2 haplotypes. Human Immunol 2002;63:677-82.

The Journal is launching a new section devoted to 'Pediatric Gastroenterology \& Hepatology' to emphasize contributions from our pediatric colleagues. Although the Journal currently receives many manuscripts with a pediatric theme, we encourage more submissions, including original research and reviews, to highlight the great depth of the discipline in Canada and internationally. The readership will easily identify these articles as they will be grouped in a feature section, and we will regularly invite commentaries and editorials to identify key differences between pediatric and adult practice. 


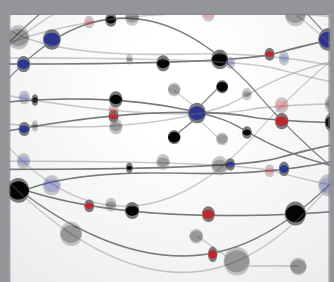

The Scientific World Journal
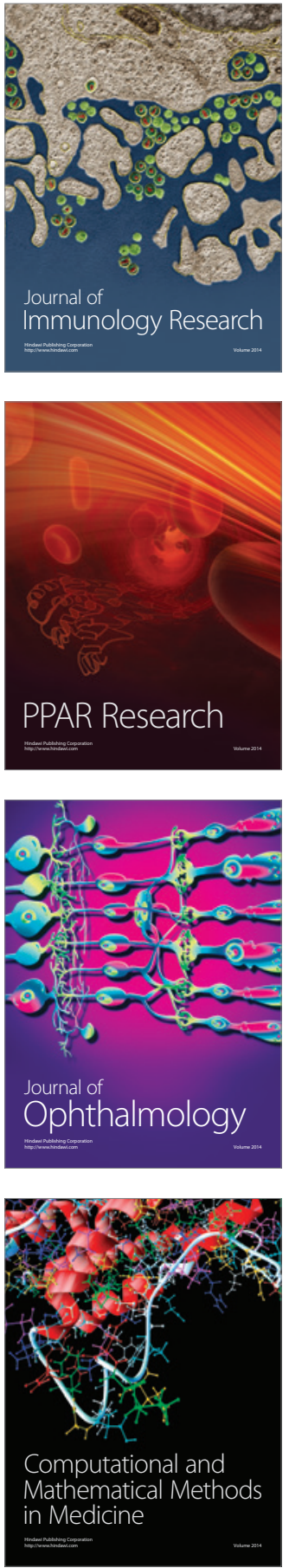

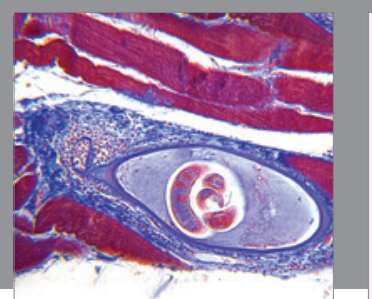

Gastroenterology Research and Practice

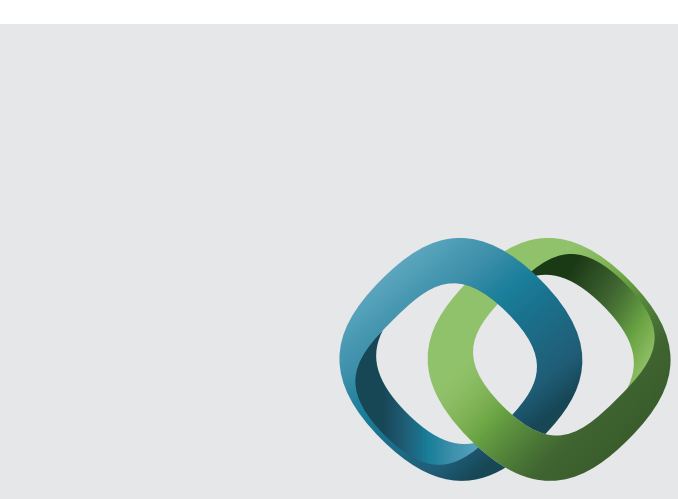

\section{Hindawi}

Submit your manuscripts at

http://www.hindawi.com
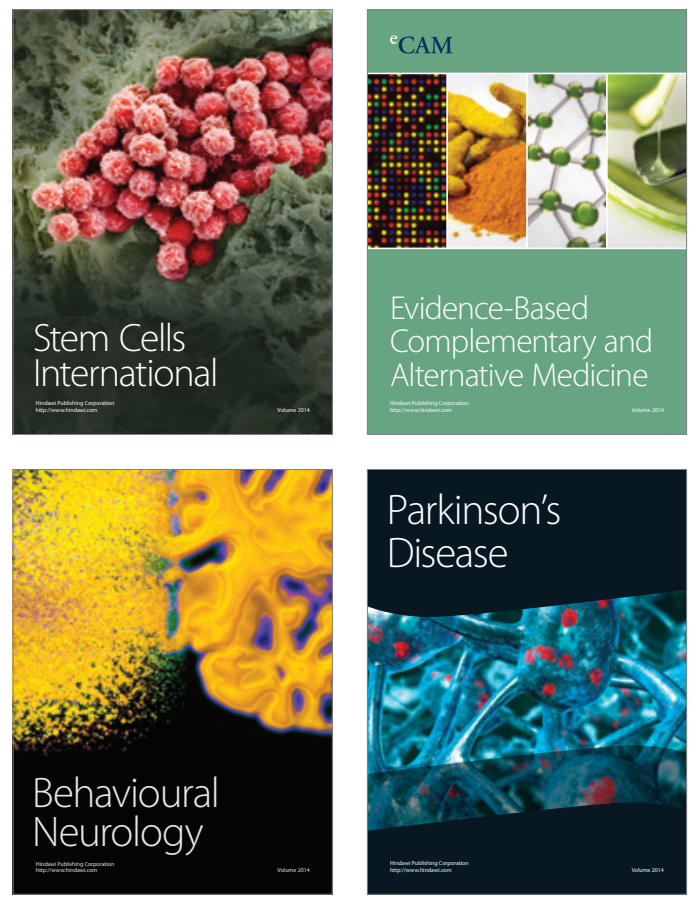
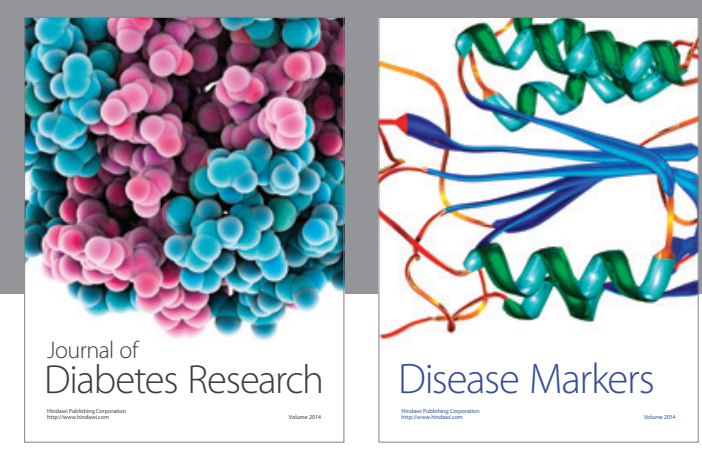

Disease Markers
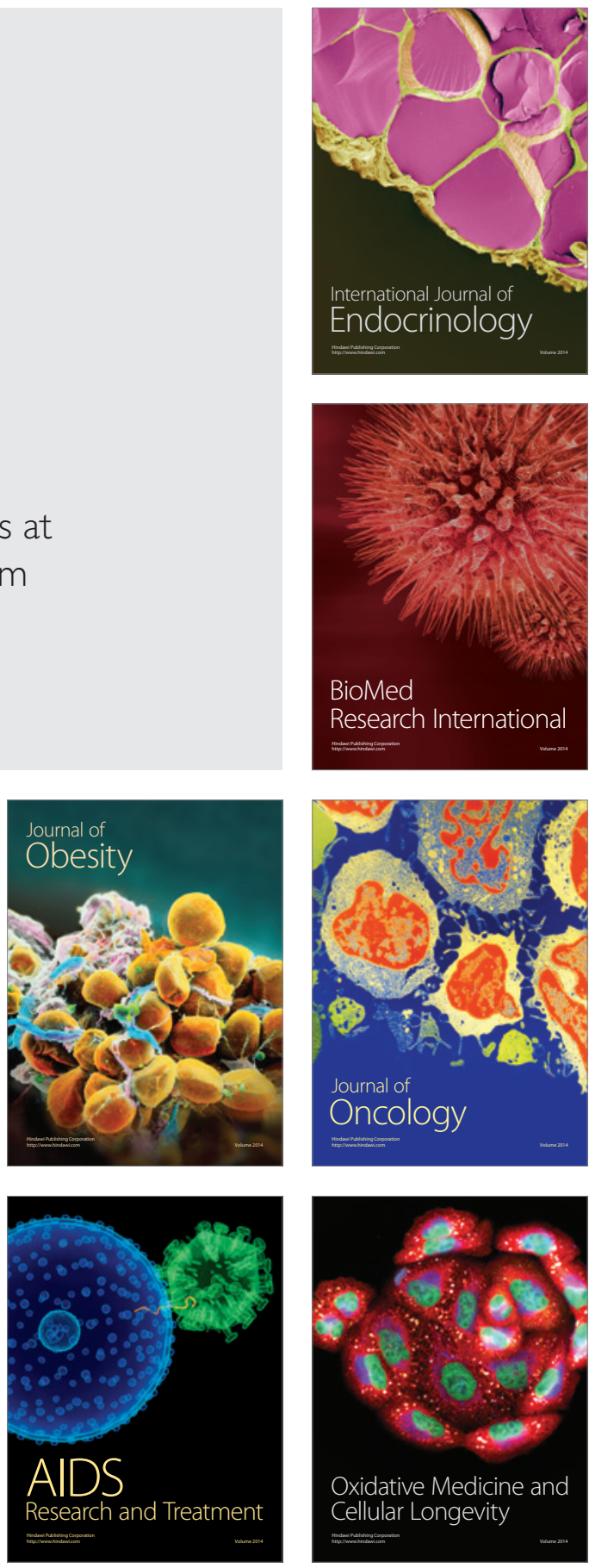